\title{
Design and computational fluid dynamic modeling of a municipal solid waste incinerator for Kampala city, Uganda
}

\author{
F. Ayaa ${ }^{1}$, P. Mtui ${ }^{2}$, N. Banadda ${ }^{1}$, J. Van Impe ${ }^{3}$ \\ ${ }^{1}$ Department of Agricultural and Bio-Systems Engineering, Makerere University, Kampala, Uganda \\ ${ }^{2}$ Department of Mechanical Engineering University of Dar-es-Salaam, Dar-es-Salaam, Tanzania \\ ${ }^{3}$ Department of Chemical Engineering, Ku Leuven, Leuven, Belgium
}

\section{Email address:}

fayaa@caes.mak.ac.ug (F. Ayaa),plmtui@yahoo.com (P. Mtui), banadda@caes.mak.ac.ug (N. Banadda), jan.vanimpe@cit.kuleuven.be (J. V. Impe)

\section{To cite this article:}

F. Ayaa, P. Mtui, N. Banadda, J. Van Impe. Design and Computational Fluid Dynamic Modeling of a Municipal Solid Waste Incinerator for Kampala City, Uganda. American Journal of Energy Engineering. Vol. 2, No. 3, 2014, pp. 80-86. doi: 10.11648/j.ajee.20140203.12

\begin{abstract}
In Uganda, the government targeted to produce at least 15 MW from Municipal Solid Wastes (MSW) by end of 2012, which was not achieved. It is against this background that this project's twofold objective is to explore the energy potential of MSW in Kampala and design an environmentally friendly waste-to-energy incinerator for electricity generation. The obtained waste characterization results show that the average composition of MSW in Kampala city varied as follows: food and yard waste, $90.64 \%$; papers, $1.67 \%$; plastics, $1.77 \%$; polyethylene, $2.99 \%$; textiles, $0.59 \%$; glass, $1.16 \%$; metals, $0.15 \%$ and others $1.03 \%$. The proximate analysis of the food and yard waste component indicated volatile matter of $73.29 \%$; fixed carbon of $4.36 \%$; moisture of $8.49 \%$ and ash of $13.86 \%$. Furthermore, the ultimate analysis of the MSW on dry basis yielded Carbon $22.58 \%$; Hydrogen $3.22 \%$; Oxygen $14.06 \%$; Nitrogen $1.56 \%$; Sulphur $0.24 \%$ and Ash $58.33 \%$. The Lower Heating Value (LHV) and Higher Heating value (HHV) of the MSW were $9.49 \mathrm{MJ} / \mathrm{kg}$ and 10.19 $\mathrm{MJ} / \mathrm{kg}$ on dry basis respectively. The HHV and LHV of the food and yard waste determined from the bomb calorimeter was $15.11 \mathrm{MJ} / \mathrm{kg}$ and $14.68 \mathrm{MJ} / \mathrm{kg}$, respectively. An incinerator was designed to suit the characteristics of the MSW and optimized using ANSYS Computational Fluid Dynamics (FLUENT Version 14, 2011). The total time needed to incinerate the waste was 31 minutes in comparison to 25 minutes for typical incinerators. The optimal capacity of the incinerator is also $460 \mathrm{~kg} / \mathrm{hr}$ as opposed to the design capacity of $567 \mathrm{~kg} / \mathrm{hr}$.
\end{abstract}

Keywords: Waste Characterization, Computational Fluid Dynamics, Municipal Waste, Incineration

\section{Introduction}

One of the biggest challenges to solid waste management in developing countries is the lack of training, knowledge and skills, experience sharing and suitable technologies to handle ever growing volumes of municipal solid waste. According to[17], most municipal authorities in developing countries concentrate their limited finances available for MSW to richer areas of the municipalities where citizens with more political power reside. The urban poor are in most cases neglected and hence suffer from most of the life threatening conditions caused by a deficient solid waste management system. It is therefore important that municipal engineers and planners in developing countries develop and implement solid waste management approaches that are effective, viable and sustainable[8]. It suffices to mention that the current market for solid waste management technologies offers either too simple systems that require large land areas that will be less and lessavailable in urbanizing Africa or too complicated and are capital intensive and complex to operate. They also require a lot of energy input when many African countries are suffering a deficit in energy supply. Moreover, these systems do not benefit from the value of solid waste management i.e. nutrients and energy (biogas) recovery. Municipal waste in Uganda is generally composed of wet carbon and nitrogen rich materials that include: organic waste from households, agro-industrial waste (slaughter houses, food industry) and 
agro waste: manure and straw [10]. The volume of solid waste generated in urban centers of Uganda is increasing as a result of growing urban population, concentration of industries, consumption of residents, and inadequate finance and facilities to manage waste collection and disposal[12]. Approximately 1,500 tonnes of solid waste are generated in Kampala city daily [7]. Currently, municipal solid waste (MSW) is landfilled, openly burnt or haphazardly dumped. There is no control of greenhouse emissions or leachate at the landfill in Kiteezi, making it an enormous environmental risk. The need for suitable and tailored technologies for solid waste management in Uganda cannot be overemphasized.

The Uganda government targeted to produce at least 15 MW from MSW by end of 2012 and 30 MW by 2017[10]. Uganda has for a long time relied solely on hydropower for grid electricity but prolonged droughts have been a key factor to unreliable power supply [2]. Biomass, which supplies $90 \%$ of the country's energy requirements, is threatened by the rapid deforestation rates. MSW is an untapped energy resource that has the ability to bridge the energy gap in Uganda. Incineration is a proven commercial technology and second most popular after landfilling. Experiences from the developed parts of the world indicate that business opportunities can be created along MSW treatment value chain to support livelihoods and clean the environment in communities by principally recovering materials (recycling), recovering energy, bio-converting to fuel and compost, and land filling of the remaining residues. One of the biggest challenges developing countries like Uganda face is the lack of tailor made technologies that are linked with MSW characteristics so that the output can be exploited in a useful manner to benefit communities.

Computational fluid dynamic (CFD) analysis of thermal flow in the combustion chamber of a solid waste incinerator could providecrucial insight into the incinerator's performance [15]. CFD also makes it possible to evaluate velocity, pressure, temperature, and species concentration of fluid flow throughout a solution domain, allowing the design to be optimized prior to the prototype phase [1]. It is against this background that this project seeks to design an environmentally friendly waste to energy incinerator, which can be used for electricity generation for especially households in Kampala city and use CFD modeling to optimize the incinerator design.

\section{Materials and Methods}

\subsection{Study Area}

This study was carried out at Kiteezi landfill, located about $12 \mathrm{~km}$ from the Kampala city center as shown in Fig. 1. The Kiteezi landfill covers 20 acres and is currently operated by the private company, Otada Construction Company. Truck crawlers are used to spread and scatter the waste in an effort to stimulate decomposition. Sometimes the waste is sprayed with insecticide to kill off flies before it is covered with soil[11]. The landfill has a leachate treatment plant which uses mechanical aeration to reduce the Chemical oxygen demand of the leachate before it's released to the environment. Kiteezi landfill receives waste from Kampala city and surrounding areas but for this study the focus was on the waste received from Kampala city. Kampala, the capital city of Uganda is located $0^{\circ} 15^{\prime} \mathrm{N}$ and $32^{\circ} 30^{\prime} \mathrm{E}$. It has a total area of $190 \mathrm{~km}^{2}[9]$. The city is experiencing rapid population growth due to immigration and natural increase[11] and it is estimated to have a population of 1.5 million inhabitants[7]. Kampala city has five divisions with Kawempe division being the poorest and central division which includes the Central Business District (CBD) being the wealthiest of them all[4]. Makindye division is mainly a residential area having a mixture of very low income and medium to high income areas in addition to being generally peri-urban in nature [11]. Kampala's other divisions are Rubaga and Nakawa.

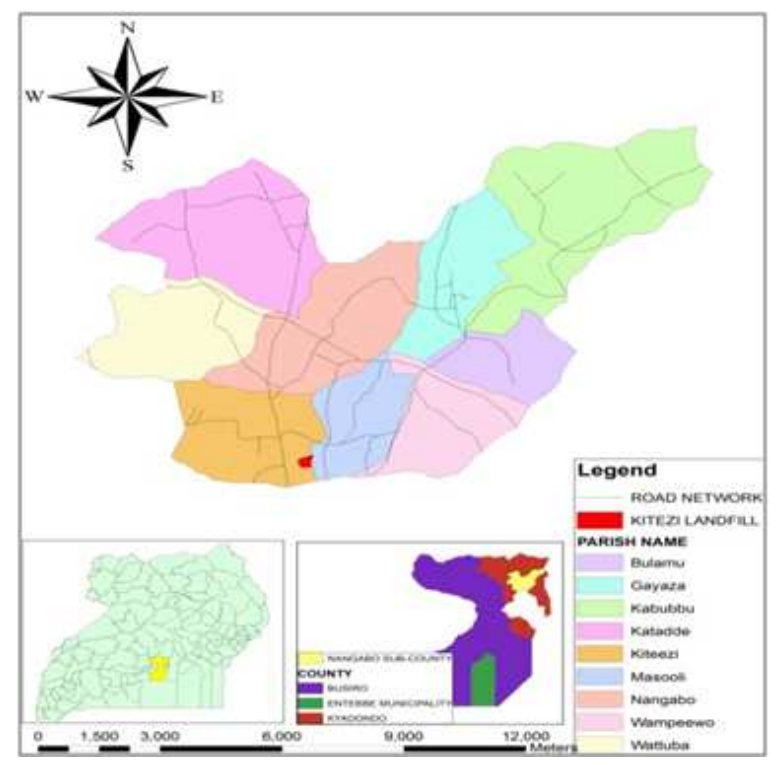

Figure 1. Kiteezi Landfill, Kampala (Uganda).

\subsection{Determining the Physical Composition of the Waste}

Trucks offloading solid waste at Kiteezi landfill, one from each of the five different divisions of Kampala, were randomly selected on each day of the analysis. The selected truck was then directed to empty its contents in the section of the landfill that was preselected for this study. Waste pickers (also known as scavengers) employed for analysis, assisted in manually sorting the waste into the different fractions given by[17] namely organics, hard plastics, metals, papers, soft plastics (polythene), glass, textiles and leather. All the other materials that were not classified into any of the previously fractions were considered to belong to the faction of others and this included items like medical wastes, inert items like soil and ash etc. The weights of the different fractions were then obtained and recorded in a data sheet by a research assistant before the proportion of the different fractions in the waste was calculated for each division. The organic fraction from each division was then thoroughly mixed up with the aid of spades and fork hoes before being spread out. A 5 by 2 grid was made on the spread out organic 
waste before 10 samples each weighing one kilogram were randomly picked from each grid. These samples were then mixed together to form one sample. From this sample, a new final sample weighing one kilogram was drawn and then placed into tightly sealed plastic bag before being taken to the laboratory for nutrient and energy content analysis respectively. This procedure was repeated for the organic waste in the other trucks selected from the different divisions of Kampala for thirty consecutive days and thereafter for two consecutive days after every two months. Samples were collected for a period of four months (September to December, 2012) on a weekly basis.

\subsection{Proximate Analysis of the MSW}

In determining moisture content of the samples, about $5 \mathrm{~g}$ of the sample brought in from the field, was weighed in to a dish that had been dried in an oven and weighed. The uncovered dish was then dried in an oven at $105^{\circ} \mathrm{C}$ for about three hours. The dish was covered and was transferred to desiccators and weighed as soon as the dish was cooled. The heating and weighing procedure was repeated until successive weight did not differ by more than one milligram. Loss in weights was recorded. The sample procedure is repeated for two other sub-samples and the average moisture content of the three sub-samples is taken to be the moisture content of the sample.

\subsection{Ultimate Analysis \& Heating Value Determination}

The ultimate analysis of the MSW was estimated using the heat and material balance software [14]whereas the heating value of the MSW was determined byforming $1 \mathrm{~g}$ of the sample into a pellet. The pellet was placed in the sample pan of the bomb calorimeter (GallenKamp autobomb, United Kingdom, CAB001.ABC.C) and the energy content of the sample is determined following the procedure of [6].

\subsection{Computational Fluid Dynamic (CFD) Modeling}

The incinerator was designed using[16] and the geometry drawn in Solid Edge V 16, meshed and optimized using ANSYS Computational Fluid Dynamics (FLUENT Version 14, 2011). An Eulerian multiphase model was used. The energy conservation equation was solved for both solid and gaseous phases. Heterogeneous and homogeneous reactions were defined in the model to express the detailed combustion kinetics in the furnace. The design was optimized to suit the characteristics of the MSW through several iterations.

\section{Results and Discussions}

The physical composition of the MSW in Kampala is depicted in Fig 2. The major components of the MSW in decreasing order are agricultural waste, namely, food and yard waste, polyethylene, plastics, papers, glass, rubber, textiles and metals.

The proximate analysis of the MSW shown in Table 1 was used to define the solid waste.
Table 1. Proximate analysis of food and yard waste.

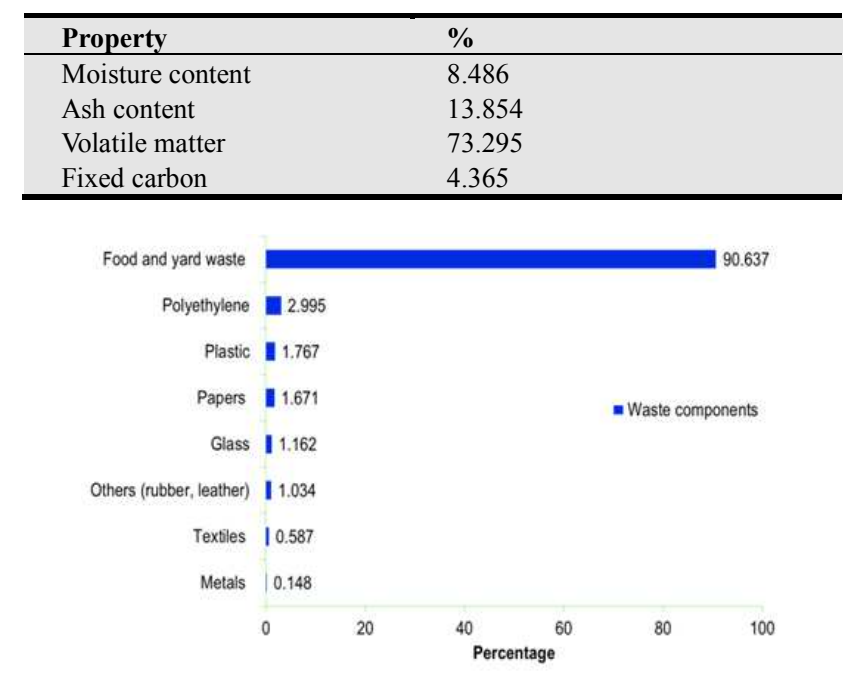

Figure 2. MSW composition of Kampala City (Uganda).

Table 2. Ultimate analysis of MSW (Dry basis)

\begin{tabular}{cc}
\hline Component & Weight \% \\
\hline C & 22.58 \\
H & 3.22 \\
O & 14.06 \\
N & 1.56 \\
S & 0.24 \\
Cl & 0.00 \\
F & 0.00 \\
Ash & 58.33 \\
Total & 100.0 \\
\hline
\end{tabular}

Table 2 shows the ultimate analysis of the MSW on dry basis. The ash content of the municipal waste from Kampala is high.The heat content of the food and yard waste and mixed MSW is shown in Table 3. The lower heating value (LHV) of the waste was approximately $9.49 \mathrm{MJ} / \mathrm{kg}$. This energy content is highly suitable for a thermal energy conversion process. The minimum calorific value of waste should be higher than $6 \mathrm{MJ} / \mathrm{kg}$ in order to meet the temperature requirement of combustion[3].

Table 3. Energy content of $M S W$

\begin{tabular}{lll}
\hline MSW & \multicolumn{2}{l}{ Heating value $\mathbf{M J} / \mathbf{k g}-$ dry } \\
\hline & HHV & LHV \\
Food and yard waste & 15.11 & 14.68 \\
Mixed MSW & 10.19 & 9.49 \\
\hline
\end{tabular}

However, a heating value of about $11 \mathrm{MJ} / \mathrm{kg}$ is needed to sustain combustion.An auxiliary fuel is thus required if the waste is to be incinerated.

In this study, the incinerator geometry used for simulation is shown in Fig. 3. The incinerator is symmetrical. MSW is fed from the top right which is the main air inlet. Also, two primary air inlets and a secondary air inlet were incorporated in the design to provide additional air for combustion. The incinerator walls were assumed adiabatic. The grate of the furnace was considered stationary during the simulations. The computational mesh generated from the incinerator geometry is shown in Fig. 4 consisting of polyhedral shapes. 
The main model input parameters are summarized in Table 4.The location of the primary and secondary air inlets was optimized iteratively to achieve maximum utilization of air for complete combustion of the MSW. During simulation, Eulerian-Eulerian approach was considered for the gas-liquid phases system.

Table 4. Design criteria and operating conditions for incinerator

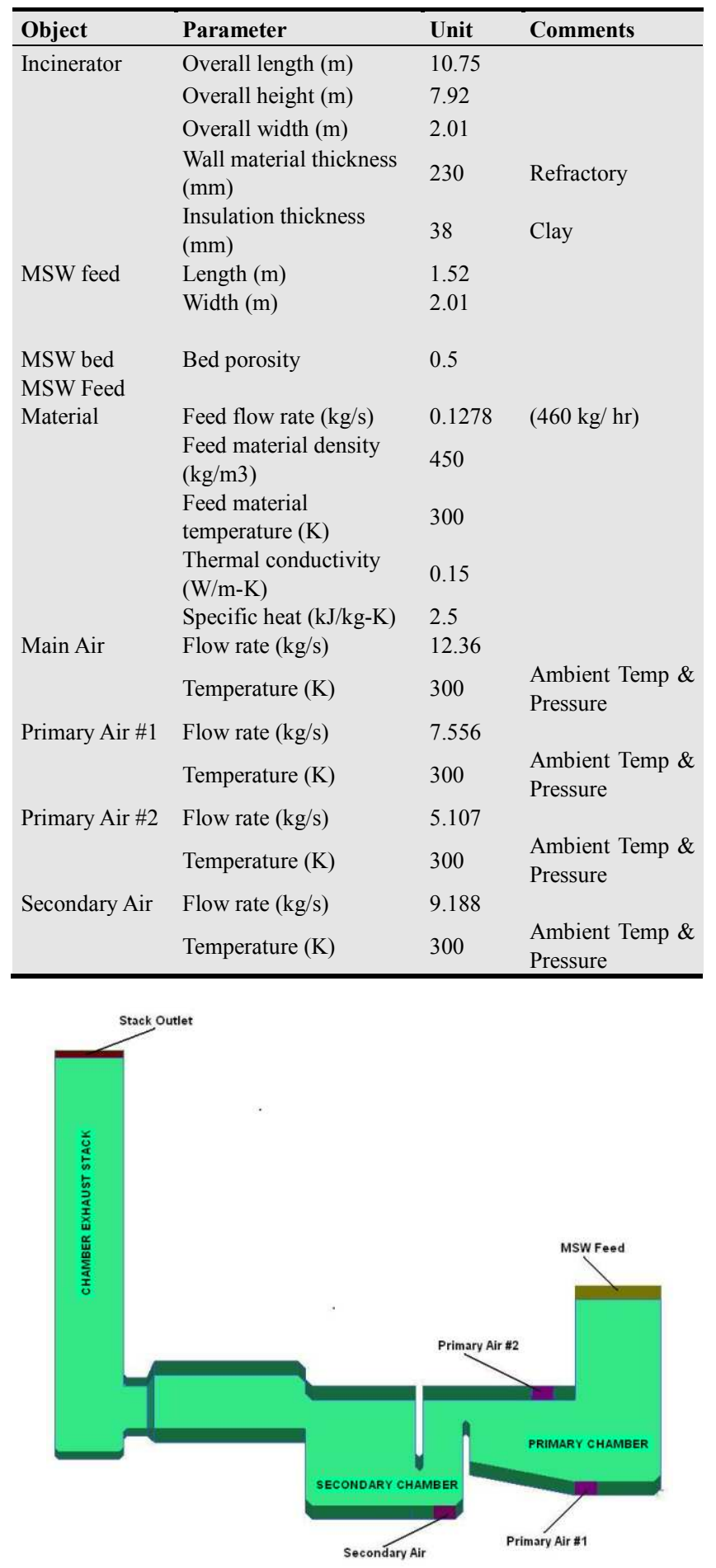

Figure 3. Incinerator geometry.

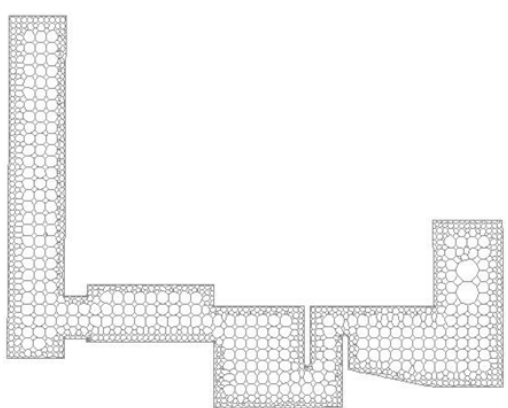

Figure 4. Mesh of incinerator geometry.

In contour plots (Fig 5-14) hereafter, the red and blue color represents the maximum and minimum values, respectively. The temperature profile inside the incinerator is shown in Fig. 5. The average temperature reached in the incinerator is about $2000 \mathrm{~K}\left(1727^{\circ} \mathrm{C}\right)$ and the lowest temperature inside the incinerator is $300 \mathrm{~K}$ which corresponds with MSW feed temperature. However, from the 3D perspective, there are high temperature zones in the incinerator as shown in Fig. 6. A uniform temperature of the gases is achieved in the exhaust stack unlike in the primary or secondary chambers. The charging hood, as would be expected has a temperature of $300 \mathrm{~K}$ because the municipal solid waste is fed in at ambient temperature. There is a burner located inside the primary chamber (Fig. 7). Ignition is initiated at a temperature of $480 \mathrm{~K}$ and is increased until self-sustaining combustion of the MSW is achieved.

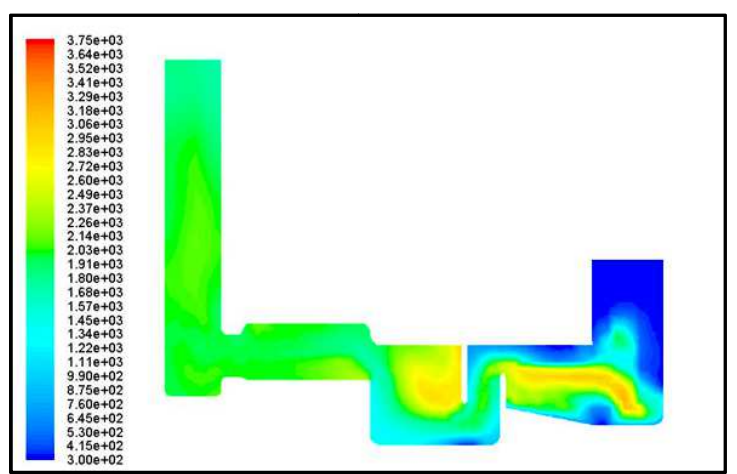

Figure 5. Static temperature of MSW-gas (K) across vertical mid-plane of the incinerator.

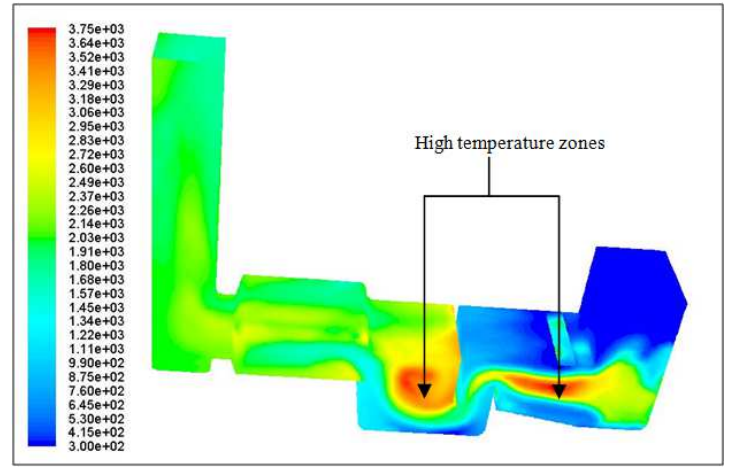

Figure 6. Temperature of MSW in a $3 D$ view. 


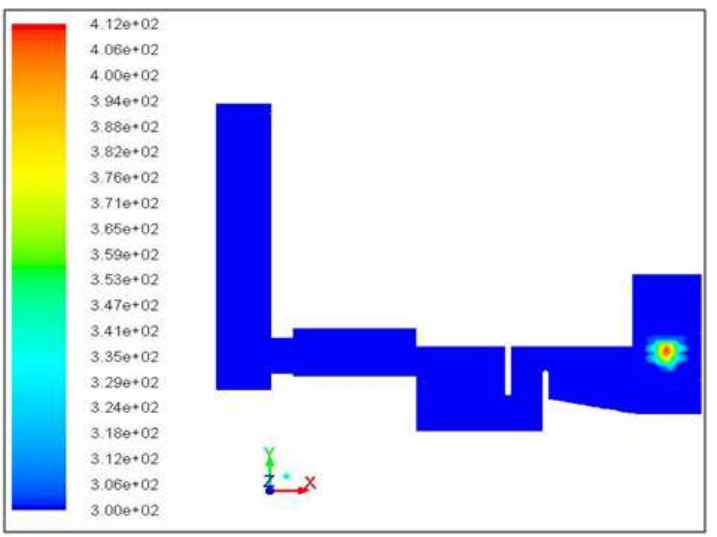

Figure 7. Position and temperature (K) of burner.

Fig 8 depicts MSW as enters the incinerator from top right at a concentration of about 0.867 (mass fraction). As expected, the concentration quickly drops down as the MSW devolatilizes as it reaches the secondary chamber where the temperature is high (See Fig. 5 and 6). The volatile species include tar, water, char and non-condensable gases.

Figure 9 depicts moisture concentration in the incinerator. As expected, the moisture is quickly evaporated as the MSW enters the secondary chamber where the temperature is high.Since MSW contains large percentage of volatiles, it produces large quantities of tar when pyrolysed as shown (Fig. 10). The tar falls onto the incinerator bed and quick is cracked to char and non-condensable gases (see Fig. 11). It is seen that large quantities of char is formed in the primary chamber. The char is deposited at the bed where it undergoes heterogeneous reactions (Table 5). Some of the char is combusted to provide heat in order to sustain the incineration process. It is observed that almost all of the char is consumed in the primary chamber.

Fig. 12 depicts very small quantities of carbon monoxide escaping from the exhaust stack. An insignificant amount of $\mathrm{CO}$ at exhaust implies all the carboneous material of MSW has been fully incinerated. Fig. 13 shows the concentration (mass fraction) of oxygen in the incinerator. Large quantities of unconsumed oxygen corresponds to the intake of MSW at top right. Also, as expected, higher $\mathrm{O}_{2}$ concentrations are visibly seen at the locations of primary and secondary inlets. However, it is clearly seen that the oxygen is nearly completed at the exhaust stack, indicating that the MSW is fully incinerated with about $0.5 \%$ oxygen at stack exist.

Fig. 14 is a contour plot depicting the concentration of water vapor in the incinerator. It is seen that large quantities of water vapor emanate from the exhaust stack as product of combustion as well as from the raw moist MSW.

Incinerators that have been constructed and tested and have been found to be satisfactory have an operating cycle of $7 \mathrm{~h}$ of charging at 25 minute intervals, and a burn down through the next $17 \mathrm{~h}$ [13]. The total flow time obtained during the simulations was however 31 minutes, therefore municipal solid waste from Kampala requires a longer combustion period compared to typical solid waste. This is because the waste has a high percentage of organic waste as previously stated and high moisture content. The incinerator capacity obtained during simulations is $460 \mathrm{~kg} / \mathrm{hr}$. unlike the design capacity of $567 \mathrm{~kg} / \mathrm{hr}$. This is critical during loading, to ensure complete combustion of the waste.

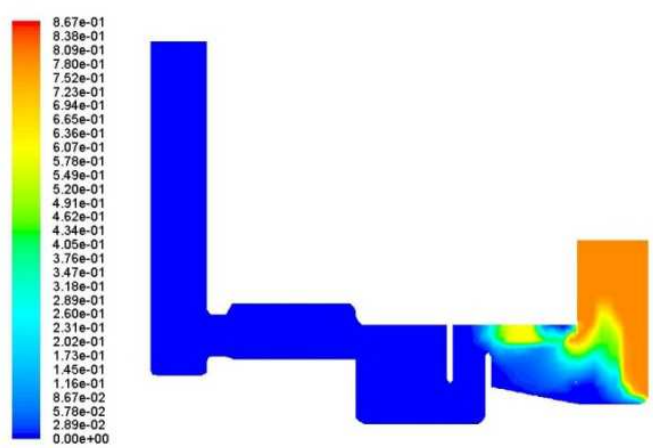

Figure 8. Mass fraction of Municipal solid waste (Dry Ash free).

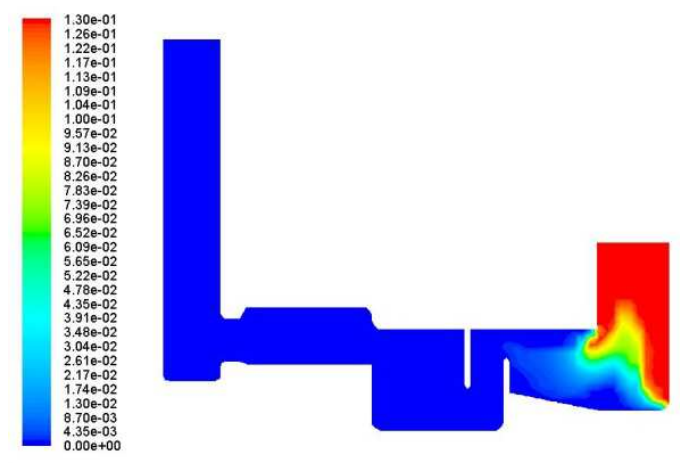

Figure 9. Mass fraction of moisture.
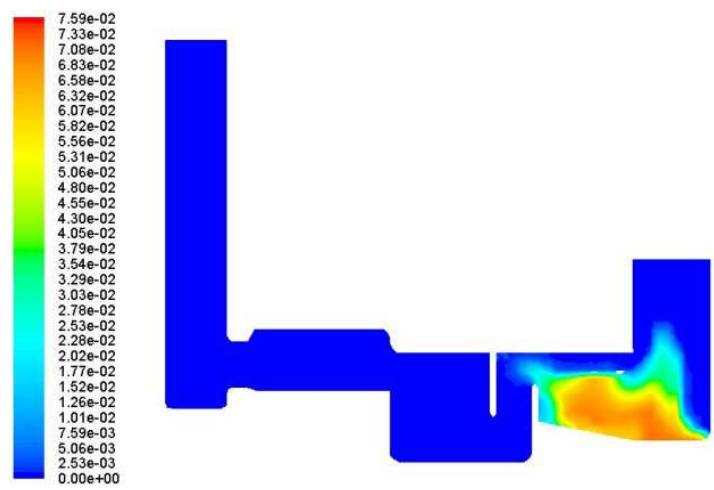

Figure 10. Mass fraction of tar.
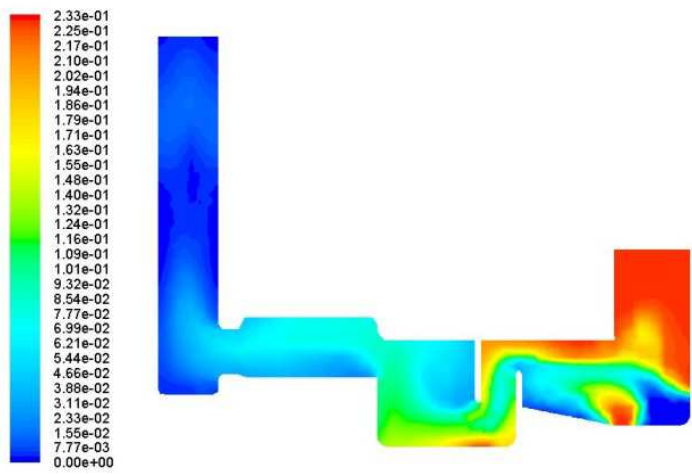

Figure 11. Mass fraction of Char 


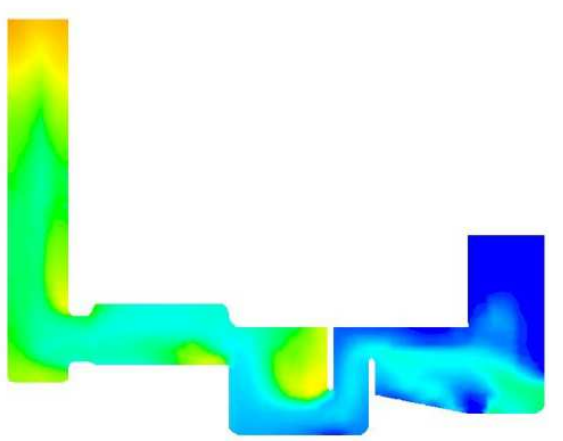

Figure 12. Mass fraction of carbon monoxide.
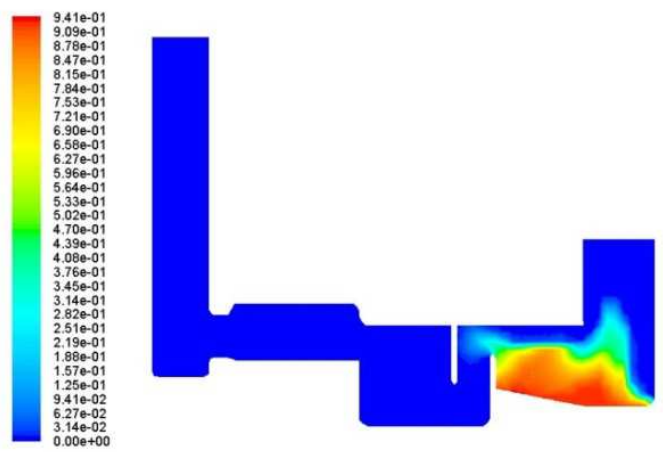
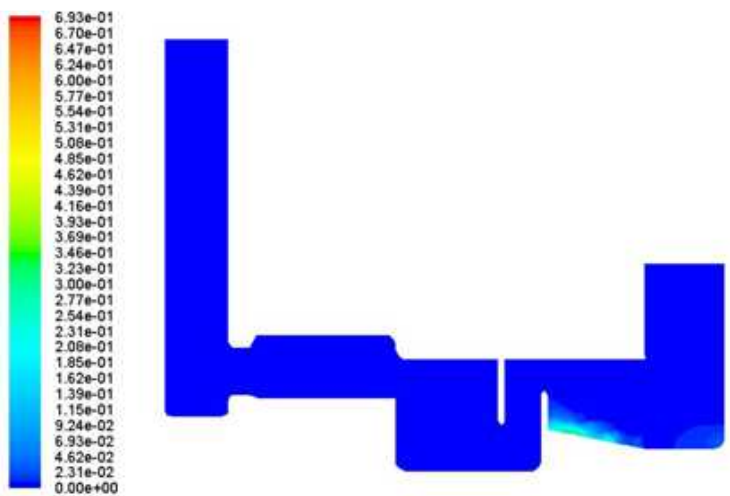

Figure 14. Mass fraction of water vapor.

Figure 13. Mass fraction of Oxygen

Table 5. Heterogeneous and homogeneous chemical reactions.

\begin{tabular}{|c|c|c|c|c|}
\hline & Process & Chemical Reaction & $\begin{array}{l}\text { Pre-exponential } \\
\text { factor }(s-1)\end{array}$ & $\begin{array}{l}\text { Activation } \\
\text { Energy(J/kmol) }\end{array}$ \\
\hline 1 & Drying & $\mathrm{H} 2 \mathrm{O}(\mathrm{l}) \rightarrow \mathrm{H} 2 \mathrm{O}(\mathrm{g})$ & $2.56 \mathrm{E}+02$ & $8.79 \mathrm{E}+04$ \\
\hline 2 & Pyrolysis & $\begin{array}{l}\mathrm{C}_{6} \mathrm{H}_{10} \mathrm{O}_{4} \rightarrow 2.33 \mathrm{CH}_{2.92} \mathrm{O}_{0.938}+3.087 \mathrm{C}+0.0272 \mathrm{CH}_{4}+0.233 \mathrm{CO}+0.3298 \mathrm{CO}_{2}+ \\
0.6599 \mathrm{H}_{2}+0.9277 \mathrm{H}_{2} \mathrm{O}(\mathrm{g})\end{array}$ & $1.0715 \mathrm{E}+2$ & $7.78 \mathrm{E}+4$ \\
\hline 3 & Tar cracking & $\mathrm{CH}_{2.92} \mathrm{O}_{0.938} \rightarrow 0.39411 \mathrm{CH}_{4}+0.572 \mathrm{CO}+0.0579 \mathrm{CO}_{2}+0.282769 \mathrm{H}_{2} \mathrm{O}(\mathrm{g})$ & $1.0715 \mathrm{E}+2$ & $6.63 \mathrm{E}+07$ \\
\hline 4 & $\begin{array}{l}\text { Gasification } \\
1 \text { - Water-gas }\end{array}$ & $\mathrm{C}+\mathrm{H}_{2} \mathrm{O}(\mathrm{g}) \rightarrow \mathrm{CO}+\mathrm{H}_{2}$ & $1.00 \mathrm{E}+08$ & $1.26 \mathrm{E}+08$ \\
\hline 5 & $\begin{array}{l}\text { Gasification } \\
2 \text { - Bourdard }\end{array}$ & $\mathrm{C}+\mathrm{CO}_{2} \rightarrow 2 \mathrm{CO}$ & $1.00 \mathrm{E}+08$ & $1.125 \mathrm{E}+08$ \\
\hline 6 & $\begin{array}{l}\text { Gasification } \\
\text { 3-methanation }\end{array}$ & $\mathrm{C}+2 \mathrm{H}_{2} \rightarrow \mathrm{CH}_{4}$ & $1.00 \mathrm{E}+05$ & $1.26 \mathrm{E}+08$ \\
\hline 7 & Water-gas-shift & $\mathrm{CO}+\mathrm{H}_{2} \mathrm{O} \rightarrow \mathrm{CO}_{2}+\mathrm{H}_{2}$ & 13.89 & $1.26 \mathrm{E}+07$ \\
\hline 8 & Oxidation 1 & $\mathrm{C}+\mathrm{O}_{2} \rightarrow \mathrm{CO}_{2}$ & $4.75 \mathrm{E}+05$ & $2.00 \mathrm{E}+08$ \\
\hline 9 & Oxidation 2 & $\mathrm{CO}+0.5 \mathrm{O}_{2} \rightarrow \mathrm{CO}_{2}$ & $2.239 \mathrm{E}+05$ & $1.7 \mathrm{E}+08$ \\
\hline 10 & Oxidation 3 & $\mathrm{H}_{2}+0.5 \mathrm{O}_{2} \rightarrow \mathrm{H}_{2} \mathrm{O}(\mathrm{g})$ & $9.87 \mathrm{E}+07$ & $3.10 \mathrm{E}+07$ \\
\hline 11 & Oxidation 4 & $\mathrm{CH}_{4}+\mathrm{O}_{2} \rightarrow \mathrm{CO}+2 \mathrm{H}_{2} \mathrm{O}$ & $2.11 \mathrm{E}+10$ & $2.02 \mathrm{E}+08$ \\
\hline
\end{tabular}

\section{Conclusion and Recommendation}

The major components of the MSW are agricultural waste, namely, food and yard waste. Also in this study, the incinerator design was successfully optimized using computational fluid dynamic (CFD) modeling. The process was iterative to achieve complete combustion in the incinerator. The design model was optimized to suit the characteristics of the MSW through several iterations. The total time needed to incinerate the waste was 31 minutes in comparison to 25 minutes for typical incinerators. The capacity of the incinerator is $460 \mathrm{~kg} / \mathrm{hr}$ as opposed tothe design capacity of $567 \mathrm{~kg} / \mathrm{hr}$. The residence time of the particles inside the chamber was not sufficiently predicted. There is need therefore for further study to optimize the incinerator design with the residence time. It was also assumed that the grate was stationary, but to for proper mixing of the waste, it is recommended that the grate is moving. CFD simulations of a moving grate would give a more accurate solution and should thus be explored. In conclusion, municipal solid waste from Kampala is suitable for incineration and it is recommended for a prototype to be constructed to obtain experimental results. These results can 
be used to upscale the technology to commercial scale for electricity production.A study to design the auxiliary equipment for the incinerator is also recommended. The socio-economic implications of the incinerator for Kampala were not studied during this research and thus need to be explored in another study.

\section{References}

[1] ALENTEC. Computational fluid dynamics modeling,applications for engineering solutions. [Online] [Cited:January16,2013.]http://www.alentecinc/com/papers/C FD/Statement $\% 20$ of $\% 20$ Qualifications-CFD.pdf.

[2] Electricity Regulatory Authority. Constraints to investment in Uganda's electricity generation industry. [Online]2008.[Cited:January16,2012.]http://www.era.or.ug/ Pdf/constraints to investment-In\%20Generation.pdf.

[3] Green, K. Industrial Ecology and Spaces of Innovation. [ed.] Sally Randles Kenneth Green. Massachusetts : Edward Elgar Publishing, 2006. ISBN-13:978 1845420970.

[4] Golooba, M.F. "Devolution and outsourcing of municipal services in Kampala city, Uganda:An early assessment."2003. Vol. 23, pp. 405-18.

[5] Howard, G., Pedleyb,S., Barrett, M., Nalubega, M., Johal, K. "Risk factors contributing to microbiological contamination of shallow groundwater in Kampala,Uganda." 2003. Vol. 37.

[6] Jessup, R.S. Precise measurement of heat of combustion with a bomb calorimeter. [Online] 1960. [Cited:November12,2012.]http://digital.library.unt.edu/ark:/ 67531/metadc13253/m2/1/high_res_d/NBS\%20Monograph \%207.pdf.

[7] Kampala Capital City Authority. Services rendered by KCCA. www.kcca.go.ug. [Online] [Cited: February 1, 2013.]http://www.kcca.go.ug/services.php\#waste management.
[8] Kaseva, M.E. and Mbuligwe, S.E. "Appraisal of solid waste collection following private sector involvement in Dar-essalaam city,Tanzania.". 2005. Vol. 29, pp. 353-366. DOI:10.1016/j.habitatint.2003.12.003.

[9] Matagi, S.V. "Some issues of environmental concern in Kampala, the capital city of Uganda." 2002. Vol. 77, pp. 121-138.

[10] Ministry of energy and mineral development. The renewable energy policy for Uganda. s.l. : Ministry of energy and mineral development, 2007.

[11] Mugagga, F. The public-private sector approach to municipal solid waste management. How does it work in Makindye division, Kampala district,Uganda? Norwegian university of science and technology. Trondheim : s.n., 2006. Doctoral dissertation.

[12] National Environment Management Authority. "State of environment report for Uganda 2006/07.". Kampala : National Environment Management Authority, 2007.

[13] Niessen, W.R. Combustion and incineration processes. Applications in Environmental engineering. 4th. s.l. : CRC press group, 2010.

[14] - Heat and material balance spreadsheets. Combustion and incineration processes. Applications in Environmental Engineering. [Software]. s.l. : CRC press group, 2010.

[15] Ryu, C., Shin, D. and Choi, S. "Combined simulation of combustion and gas flow in a grate-type incinerator." Vol. 55., pp. 174-185.

[16] US Army Corps of Engineers. Engineering and design incinerators mobilization construction. Engineering manual No.1110-3-176. Washington DC. : US Army Corps of Engineers, 1984.

[17] Zurbrügg, C. "Urban solid waste management in lowincome countries of Asia, how to cope with the garbage crisis.". Durban, South Africa. : s.n., 2002. 